\title{
MENTAL HEALTH IN DOMESTICATED IMMIGRANT POPULATION - A SYSTEMATIC REVIEW
}

\author{
Boris Ilić ${ }^{1}$, Vesna Švab ${ }^{2}$, Biserka Sedić ${ }^{1}$, Irena Kovačević ${ }^{1}$, Adriano Friganović ${ }^{1,3}$ \& Ena Jurić ${ }^{4}$ \\ ${ }^{1}$ University of Applied Health Sciences, Department of Nursing, Zagreb, Croatia \\ ${ }^{2}$ University of Ljubljana, Faculty of Medicine, Ljubljana, Slovenia \\ ${ }^{3}$ University Hospital Centre Zagreb, Department of Anesthesiology, Reanimatology andlintensive Care, Zagreb, Croatia \\ ${ }^{4}$ Hôpital Molière Longchamp, Bruxelles, Belgium
}

received: 4.7.2017;

revised: 17.8.2017;

accepted: 24.8 .2017

\begin{abstract}
SUMMARY
Background: Migration is a process during which a person moves from one cultural setting to another in order to settle for a longer period of time or permanently. The number of immigrants in the world has more than doubled since 1975, with majority of migrants living in Europe today. Migration is now being increasingly recognized as a risk factor for multiple mental-health related issues, such as schizophrenia, psychosis, anxiety disorders and others.

Aim: The aim of this study was to collect, systematically review and analyze relevant articles pertaining to the mental health of second-or-higher generations of domesticated immigrant population, as well as to determine common socio-cultural predisposition factors leading to the development of mental illness among the mentioned population.

Methods: Systematic search of relevant and peer-reviewed electronic database ScienceDirect was performed to identify studies related to mental health and healthcare in before-mentioned immigrant population. Study selection was performed by two independent reviewers, following the agreed specific inclusion and exclusion criteria.

Results: 2036 records were identified through initial database search, out of which 5 studies were included in this review, after the selection process.

Conclusion: The most consistent clinical finding is an increase in the rate of diagnosis of schizophrenia and related psychoses among migrants when compared to the host population, however the relationship between migration and psychotic disorders remains unexplained. So far, biological factors, such as cannabis use or obstetric complications, have failed to account for the risk of schizophrenia among migrant groups. Socio-environmental factors are now being looked upon as potential contributing factors for psychotic disorders in migrants.
\end{abstract}

Key words: mental health - transients and migrants - depression - psychotic disorders - schizophrenia

$$
* * * * *
$$

\section{INTRODUCTION}

Migration is a process during which a person moves from from one cultural setting to another in order to settle for a longer period of time or permanently. The number of immigrants in the world has more than doubled since 1975, with most migrants living in Europe (56 million), Asia (50 million) and Northern America (41 million). In 1990, migrants accounted for over $15 \%$ of the population in 52 countries. Most of the migration was from developing to developed countries (Lindert et al. 2008).

Definitions of 'migrant' and 'immigrant' vary among different data sources, and between datasets and legislation (Anderson \& Blinder 2015). Relevant sources define migrant as a person that travels to a different country or place, often in order to find work or better living conditions, while immigrant pertains to a person who comes to live permanently in a foreign country.

In summary, the term migrant or immigrant could apply to all persons having left their home country either due to 'push' factors in the country of origin (i.e. asylum seekers or refugees) or due to 'pull' factors of the immigration country (i.e. economic incentives, as in the case of labor migrants).

In the light of the literature on migrant populations (Cantor-Graae \& Selten 2005, Veling et al. 2006, Veling et al. 2011, Termorshuizen et al. 2012) we defined an immigrant as first generation (a subject born abroad), second generation (at least one parent born abroad), or third generation (at least one grand-parent born abroad) and focused this review on the second-orhigher generations.

\section{Migration and mental health}

The most consistent clinical finding is an increase in the rate of diagnosis of schizophrenia and related psychoses among migrants when compared to the host population (Gupta 1993, Haasen et al. 2000). Most of these studies concerned first-generation migrants (Gupta 1993), but several relevant data demonstrated that secondgeneration migrants also presented an increased risk for psychosis (Goodman \& Richards 1995, Harrison et al. 1988, Harrison 1990, Littlewood \& Lipsedge 1998, McGovern \& Cope 1987, Selten \& Sijben 2001, Selten et al. 2001, Wessley et al. 1991). Both acute (life events) and chronic social adversity could operate as a 
contributing factor in higher rate of psychosis in both first and second-generation migrants (Harrison et al. 1997), while some sources indicate that a less desirable entry into the psychiatric system in comparison to other patients (ie. compulsory treatment, police involvement, etc.) could also be a contributing factor (Davies et al. 1996, Garrison et al. 1989, Koffman et al. 1997, Perkins \& Moodley 1993, Rwegellera 1980).

An association between migration and schizophrenia was first described by the pioneer Ödegaard (1932), who observed an increased risk among Norwegians migrants to the USA in the early twentieth century. However, only in recent decades has an interest in migration and schizophrenia been rekindled, especially after consistent reports of high incidence rates in Caribbean migrants to the UK (Harrison et al. 1997). Such elevated incidence rates were noted initially in the decades that followed large migration waves - from Commonwealth countries after the Second World War (Bourque et al. 2011).

Studies have found increased rates of schizophrenia not only among first-generation immigrants (FGIs), who have a personal history of migration, but also among the growing population of second-generation immigrants (SGIs), their children born in the host society context (Bourque et al. 2011). It was suggested that the risk may be even higher for SGIs than for FGIs (Harrison et al. 1988). More recent studies in the UK have reported that migrants are at risk for all psychoses, and not only schizophrenia.

Migration is now being increasingly recognized as a risk factor for schizophrenia, however the relationship between migration and psychotic disorders remains unexplained. So far, biological factors, such as cannabis use or obstetric complications, have failed to account for the risk of schizophrenia among migrant groups (Bourque et al. 2011). In addition, socio-environmental factors, such as urbanicity, discrimination or socioeconomic deprivation, are now being looked upon as potential contributing factors for psychotic disorders in migrants. It is uncertain whether second-generation immigrants have a similar or even a higher risk than first-generations.

\section{METHODS}

\section{Search strategy and keywords}

Systematic search of relevant and peer-reviewed electronic database ScienceDirect was performed to identify studies related to mental health and healthcare in migrant population. Search was limited to the period of past fifteen years, from 2001 to 2016 . Keywords and terms used for the search included *mental, *psych, *depress, *s, *PTSD, *stress, *anxiety, *mental health AND *refugee, *migrant, *immigrant, *asylum seeker, *transient, *ethnic, *displaced person in category Social science \& Medicine. Approximately 2036 documents were retrieved, whose titles and abstracts were initially examined for eligibility (Ustun 2002).

Additionally, to minimize the risk of missing relevant reviews, 12 documents were obtained by other sources, including the references found in the screened studies and authors' personal databases.

\section{Refining and selection of the studies}

Study selection was performed in several stages. Firstly, the obtained results were screened for eligibility, based upon previously agreed inclusion and exclusion criteria (Table 1). Inclusion criteria required a peerreviewed journal article, systematic review or original research, related to the mental health of second-orhigher generations of domesticated migrant population, published between 2001 and 2016, written in English, Croatian, Serbian or Bosnian language and with abstract available.

After the initial selection, two independent reviewers examined the titles and abstracts and decided which studies to include in the review, with any disagreements settled by consensus.

Table 1. Inclusion and exclusion criteria

\begin{tabular}{|c|c|c|}
\hline & Inclusion criteria & Exclusion criteria \\
\hline Type & $\begin{array}{l}\text { Systematic review } \\
\text { Review article } \\
\text { Original research }\end{array}$ & $\begin{array}{l}\text { Letters } \\
\text { Editorials }\end{array}$ \\
\hline Population & Second or higher generation of immigrant population & $\begin{array}{l}\text { Population currently in migration } \\
\text { First generation of immigrant population }\end{array}$ \\
\hline Keywords & $\begin{array}{l}\text { *mental, *psych, *depress, *post-traumatic stress disorder, } \\
\text { *PTSD, *stress, *anxiety, *mental health AND *refugee, } \\
\text { *migrant, *immigrant, *asylum seeker, *transient, *ethnic, } \\
\text { *displaced person }\end{array}$ & Everything else \\
\hline Date & 2001. to 2016 & Prior to 2001. \\
\hline Abstract & Abstract available & Abstract not available \\
\hline Language & $\begin{array}{l}\text { English } \\
\text { Croatian } \\
\text { Serbian } \\
\text { Bosnian }\end{array}$ & Other \\
\hline
\end{tabular}




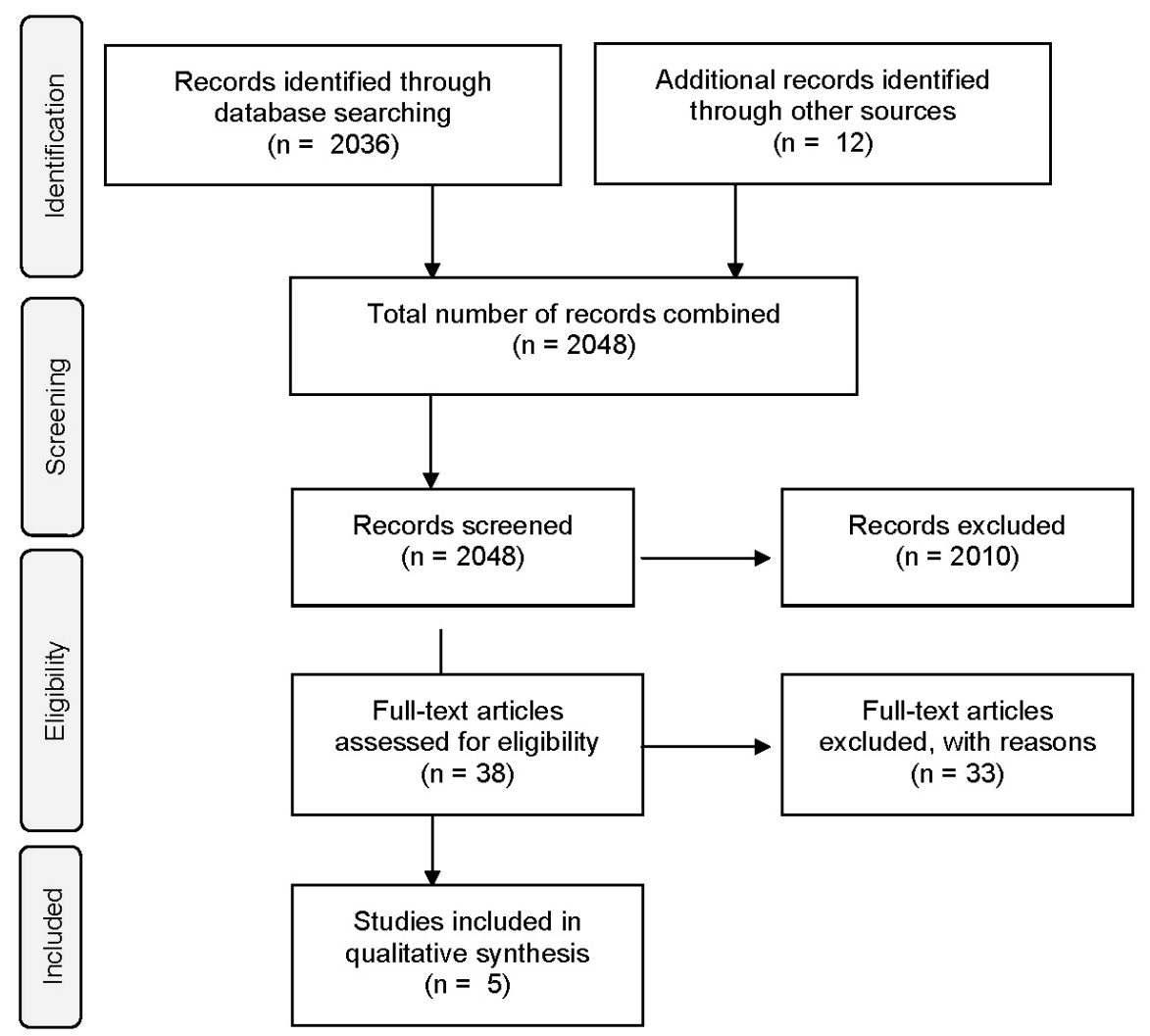

Figure 1. Search, refining and selection process (PRISMA 2009)

Process of selection, refining and selection of the studies has been shown using PRISMA 2009 Flow diagram (Moher et al. 2009), as shown in figure 1.

Excluded records were either considering population currently in migration, a first generation on immigrant population, there was no information regarding the generation or was methodologically of a less quality, according to the subjective opinions of the authors.

\section{RESULTS AND DISCUSSION}

Fossion et al. (Fossion et al. 2002) conducted a crosssectional survey on 272 patients admitted in a psychiatric emergency unit in Brussels (Belgium), during the year 1998. The aim of the study was to test the hypothesis, based on other international studies, that the migrant population shows an increase in the rate of psychosis, in comparison to the rest of the population. They used univariate and multivariate analyses to compare second-generation Moroccan migrant patients (Second-generation Moroccan migrant patients are citizens born in Belgium with at least one parent born in Morroco (28)) $(\mathrm{n}=136,86$ males, 50 females, mean age $24.4 \pm 4.03$ years) with Belgian patients $(n=136,86$ males, 50 females, mean age $24.5 \pm 3.90$ years), matched for the variables of age and gender.

In the psychiatric emergency department (PED), a psychiatrist, a social nurse and a psychiatric nurse evaluated each patient using a standardized item sheet. Sheet covered axis I diagnoses (according to the DSM-
IV criteria), clinical data (the existence of a previous psychiatric hospitalization, registration with a GP, registration with an external psychiatrist, the presence of a suicide attempt, the modalities of admission to the PED and the mode of discharge from the PED) and the social and demographic background (type of accommodation, occupation and source of income). The treating psychiatrist made an initial diagnosis, and a senior psychiatrist independently verified it by referring to case notes (Fossion et al. 2002).

They separately compared the female migrant patients with the female Belgian patients, the male migrant patients with the male Belgian patients and all the migrant patients with all the Belgian patients. For this purpose, they carried out the McNemar test for matched samples. Secondly, they entered the variables reaching statistical significance $(\mathrm{P}<0.05)$ in univariate analyses comparing all the migrant patients with all the Belgian patients as predictors into a conditional logistic regression model with "Being an migrant patient" as dependent variable (Fossion et al. 2002).

The study showed that the female migrant patients presented no significant difference when compared with female Belgian patients and that male migrant patients presented a higher rate of admission for psychotic disorders $(40 \%$ vs. $14 \%, \mathrm{P}=0.001)$ and a lower rate of admission for alcohol use disorders (5\% vs. $18 \%$, $\mathrm{P}=0.01$ ). Multivariate analyses showed that migrant patients presented a higher rate of admission for psychotic disorders when they were compared with Belgian patients matched for age and gender. 
Comparing both groups, migrant patients presented a higher rate of admission for psychotic disorders $(34 \%$ vs. $14 \%, \mathrm{P}=0.001$ ) and a lower rate of admission for alcohol use disorders ( $6 \%$ vs. $14 \%, \mathrm{P}=0.02)$.

Male migrant patients presented a lower rate of selfreferral $(34 \%$ vs. $51 \%, \mathrm{P}=0.03)$, a higher rate of admission with family involvement $(19 \%$ vs. $7 \%, \mathrm{P}=0.04)$ and a higher rate of admission with police involvement $(17 \%$ vs. $5 \%, \mathrm{P}=0.02)$, as well as a higher rate of problems related to the legal system ( $8 \%$ vs. $0 \%, \mathrm{P}=0.02)$.

Comparing the entire groups, migrant patients lived more often with their parental family ( $66 \%$ vs. $49 \%$, $\mathrm{P}=0.01$ ), and they presented a lower rate of salaried employment ( $12 \%$ vs. $23 \%, \mathrm{P}=0.03)$ and a higher rate of unemployment ( $19 \%$ vs. $10 \%, \mathrm{P}=0.02)$.

Van der Wurff et al. (2004) performed a crosssectional study on 299 Moroccan, 330 Turkish, and 304 Dutch elderly $(\mathrm{n}=933)$, aged between $55-74$ years. The aim of the study was to determine prevalence of clinically significant depressive symptoms among elderly Turkish and Moroccan migrants compared with native Dutch elderly and to determine if differences in prevalence rates were explained by known risk factors for depression and/or ethnic, migration-related factors. Potential risk factors included gender, limitations in daily functioning, marital status, chronic physical illnesses, income level, migration, ethnic origin and acculturation questions. Authors have interviewed the participants using the Center for Epidemiologic Depression Scale (CES-D), which has been commonly used in the older community population, and has good psychometric properties in older. CES-D scale is by far the most widely used instrument for epidemiological research and has been translated into more than 15 languages (Berkman et al. n.d., Foelker \& Shewchuk 1992).

Subjects in the described study were recruited as part of a cross-sectional health survey among the Amsterdam population, conducted by the municipal health service of the city of Amsterdam from October 1999 to June 2000. The aim of the survey was to obtain insight into the state of public health in Amsterdam, particularly focusing on differences in health perspective in the populations of elderly Turkish, Moroccan and native Dutch migrants. A random sample of non-institutionalized people was drawn from the Amsterdam municipal population register, aged 16 years and older. Authors then stratified the sample by gender, age and descent. Interviewers were matched to respondents on the basis of ethnic origin and gender and interviewed the respondents in their native language (Van der Wurff et al. 2004).

Country of birth of the respondent and the country of birth of the respondent's parents were used to determine the ethnic origin of the participant. If the respondent or their parents were born in Turkey or in Morocco, the respondent's ethnicity was considered Turkish or Moroccan, respectively (Van der Wurff et al. 2004).

The study showed that the level of education and income was in Turkish and Moroccan elderly extremely low compared to the native Dutch elderly $(\mathrm{P}<0.001)$. Moroccan elderly had a lower income level and suffered from more physical limitations more than Turkish elderly $(\mathrm{P}<0.05)$. Turkish elderly had more clinically significant depressive symptoms compared to the Moroccan elderly, but less than Dutch male population. The overall level of significant depressive symptoms in the total sample was considered high (38.1\%).

Remarkably, no association could be established between income level and depressive symptoms in any of the samples in this study. In the Dutch and Moroccan sample, more people living alone had clinical significant depressive symptoms. In the Dutch and Turkish sample, not being married was significantly associated with the presence of depressive symptoms. Female gender, physical limitations and chronic physical illnesses were also uniquely associated with the presence of clinical significant depressive symptoms.

Among the sample of Turkish migrants, only five items were significantly associated with depressive symptoms: having been in Turkey for once or more for a period longer than 3 months in the last 5 years, not having the opportunity to return to Turkey, having negative reasons for not returning to the home country (for example not having the financial possibilities), speaking Dutch with friends and buying food in shops of their home country. For the Moroccan sample only, having more contact with Moroccan people than native Dutch people, and the conviction that men need to take decisions on investments was associated with scores on the CES-D scale higher than 16 points (Van der Wurff et al. 2004).

Kerkenaar et al. (2013) performed a study as a part of the research project 'Ecology of Medical Care Utilization of Health Care in Austria (ECOHCARE)'. The survey was conducted by a professional Computer Assisted Telephone Interview (CATI) provider and carried out in four waves between October 2010 and September 2011, on population of $n=3509$ participants, aged 15 years and older, in order to investigate the prevalence of dysphoric disorders (depression and anxiety) among migrant population. Depression and anxiety were measured with the Patient Health Questionnaire-4 and utilization of health care services in the previous four weeks.

The questionnaire was translated into the languages of the four largest non-German-speaking migrant populations in Austria (Bosnian, Croatian, Serbian and Turkish) using state of the art back translation. If a person was not able to speak German sufficiently, a new appointment was made with an interviewer skilled in the appropriate language (Kerkenaar et al. 2013).

Participants were classified as migrants based on their country of birth and the country of birth of their parents. Participants who were born outside of Austria were considered first generation immigrants. When at least one parent was born outside of Austria, the participants were classified as second-generation immigrants. All other participants were classified as Austrians. 
Table 1. Overview of the studies included in the review

\begin{tabular}{llllll}
\hline Study & \multicolumn{1}{c}{ Aim } & \multicolumn{1}{c}{$\begin{array}{c}\text { Research type, } \\
\text { methodology }\end{array}$} & Population & $\begin{array}{c}\text { State/ } \\
\text { Country }\end{array}$ & Results \\
\hline $\begin{array}{l}\text { Fossion } \\
\text { et al. 2002 }\end{array}$ & $\begin{array}{l}\text { To confirm increase in the rate } \\
\text { of psychosis among 2 } \\
\text { generation Morrocan migrant } \\
\text { patients vs. Belgian patients } \\
\text { matched for the variables of age } \\
\text { and gender }\end{array}$ & $\begin{array}{l}\text { Cross-sectional survey on } \\
\text { 272 patients admitted in a } \\
\text { psychiatric emergency unit } \\
\text { during the year 1998. }\end{array}$ & $\begin{array}{l}\mathrm{N}=272 \\
\text { Authors used univariate and } \\
\text { multivariate analyses to } \\
\text { compare the two subgroups }\end{array}$ & $\begin{array}{l}\text { Morrocan } \\
\text { migrant } \\
\text { patients and } \\
\text { Belgian } \\
\text { patients } \\
\text { matched for } \\
\text { the variables } \\
\text { of age and } \\
\text { gender }\end{array}$ & $\begin{array}{l}\text { Multivariate analyses showed } \\
\text { that migrant patients lived } \\
\text { more often with their parental } \\
\text { family and that they presented } \\
\text { a higher rate of admission for } \\
\text { psychotic disorders and a }\end{array}$ \\
& & & $\begin{array}{l}\text { lower rate of employment } \\
\text { Unemployment is a contribu- } \\
\text { ting factor in the risk for } \\
\text { psychosis among migrant }\end{array}$ \\
& & & groups
\end{tabular}

Psychosocial stress - represented in the present study by the higher percentage of problems with the legal system and the lower percentage of employment - is a contributing factor in the risk for psychosis among migrant groups

Van Der To study the prevalence and risk Wurff factors for depression in Turkish et al. 2004 and Moroccan elderly living in the community in the Nether lands in comparison to equiva lent native Dutch population

Are differences in prevalence rates explained by known risk factors for depression such as age, sex, demographic, health-related, income and social variables or are specific ethnic factors associated with depression in elderly Turkish and Moroccan migrants?

Is there an influence of migrationrelated factors on the prevalence of depression within the groups of Turkish and Moroccan migrants?

Amad To establish prevalence of et al. 2013 psychotic disorders in migrant populations in France, and to present findings concerning third-generation migrants.
330 Turkish, 299 Moroccan, N=933 and 304 Dutch elderly (55-74 years) were interviewed (cross-sectionally) using the Center for Epidemiologic Depression Scale (CES-D)

Between 1999 and 2003, the French Mental Health in General Population (MHGP) survey, conducted by the World Health Organization Collaborating Centre (WHO$\mathrm{CC}$ ), was used to interview 37063 people. Of the 37063 individuals interviewed, 9821 were migrants

The designation of migrant status was based on the country of birth of the subject, the subject's parents and the subject's grandparents.

The Mini International Neuropsychiatric Interview (MINI, French version 5.0.0), a standardized psychiatric interview, was used to identify psychiatric disorders. 299 Moroccan, and 304

Dutch elderly (55-74 years)

Nether- The prevalence of selflands reported depressive symptoms (CES-D >=16) was very high in elderly migrants, $33.6 \%$ for Moroccan and $61.5 \%$ for Turkish elderly.

The prevalence of depressive symptoms in the native Dutch sample was similar to earlier studies in the Netherlands and abroad: $14.5 \%$.

Among migrants education and income level was very low and they had a high number of physical limitations and chronic medical illnesses.

Ethnicity was a strong independent risk factor.

$\mathrm{N}=9.821 \quad$ France

After adjustment for age, sex, level of education and cannabis use, the prevalence of single psychotic episode was significantly higher in the migrant sample in the first and the second generation compared with the non-migrant sample. 
Table 1. Continues

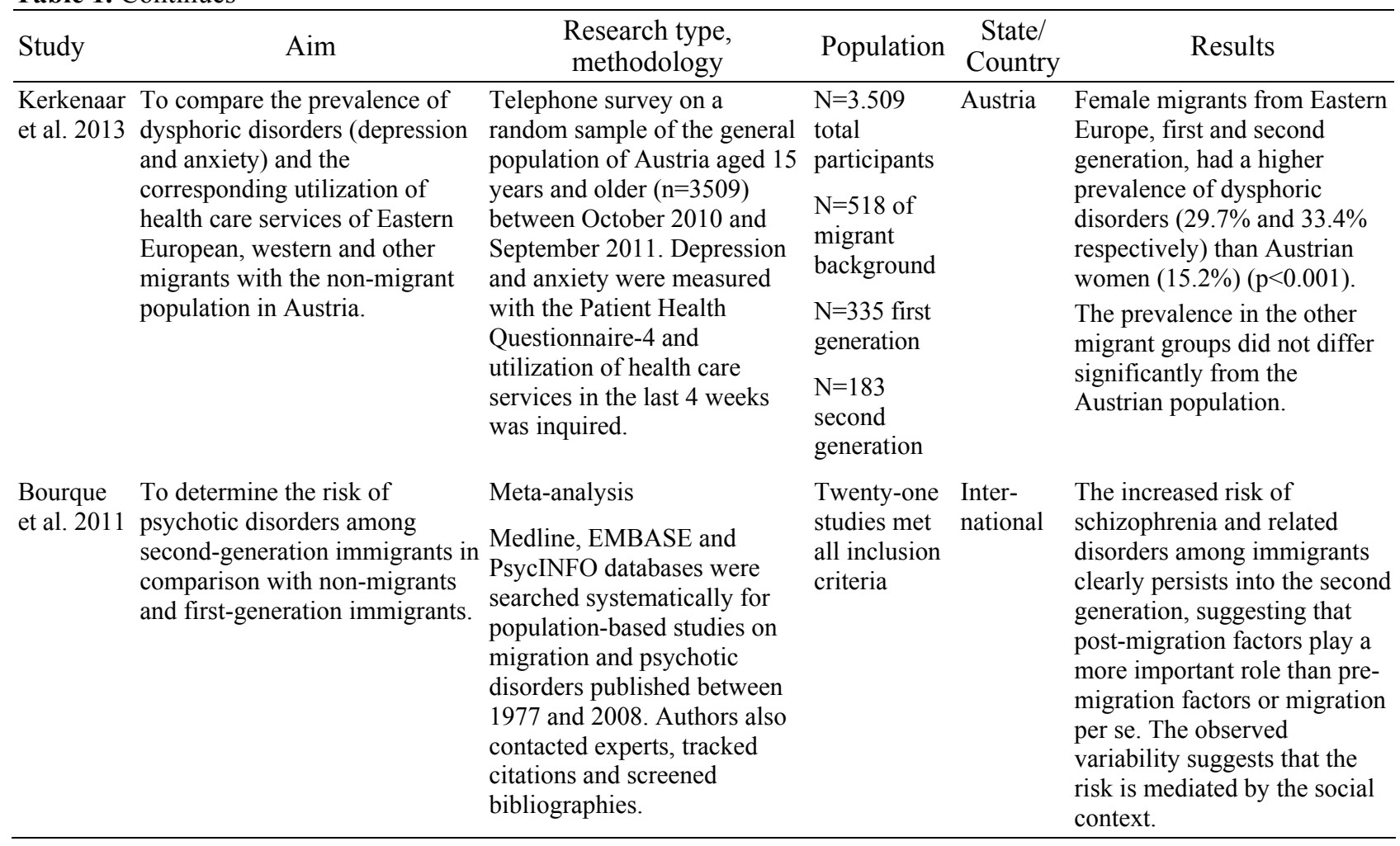

Among the male participants, the prevalence of depressive and anxiety disorders in all migrant groups was not significantly different from the Austrians $(\mathrm{P}=0.407)$. In contrast, women of the first and second generation from 'Eastern Europe' (includes the other European countries: the former Eastern Bloc countries (except Eastern Germany), Greece, Georgia and Turkey) had a higher prevalence of depressive and anxiety disorders than Austrian women $(\mathrm{P}<0.001)$. Even though the total prevalence of depressive and anxiety disorders did not differ significantly between the two generations, women from the first generation had more depression than those from the second generation $(25.2 \%$ versus $8.1 \%, \mathrm{P}=0.010)$, mostly comorbid with anxiety. The majority of the second generation had only symptoms of anxiety (Kerkenaar et al. 2013).

The group of women born in 'Eastern Europe' includes those who left former Yugoslavia after the start of the wars in 1991. The prevalence of depressive and anxiety disorders was higher in this group that experienced the wars $(65.4 \%(n=7))$ compared to the other Eastern European (24.5\%) and Austrian women $(15.1 \%)(\mathrm{P}<0.001)$. After exclusion of those women who experienced the wars in former Yugoslavia, the prevalence of depressive and anxiety disorders was still significantly higher among the Eastern European than among the Austrian women $(\mathrm{P}=0.029)$. Among men, the prevalence of depressive and anxiety disorders did not differ significantly between those who experienced the war in former Yugoslavia and the rest of the group from Eastern Europe (Kerkenaar et al. 2013).
There was no association between the length of stay in Austria in years and the prevalence of dysphoric disorders, regardless whether the analysis was performed for men and women separately (Kerkenaar et al. 2013).

Amad et al. (2013) tried to establish the prevalence of psychotic disorders in migrant populations in France and to present information regarding the third-generation migrants. Between 1999 and 2003, the French Mental Health in General Population (MHGP) survey, conducted by the World Health Organization Collaborating Centre (WHO-CC), was used to interview 37063 people, out of which 9821 were migrants. The subjects interviewed were selected by a quota sampling method and, thus, were representative of the general population in the 47 study sites in France.

At each site, the Mini International Neuropsychiatric Interview (MINI, French version 5.0.0), a standardized psychiatric interview, was used to identify psychiatric disorders. The MINI includes a psychotic disorders section with nine items. The interviewers (nurses and psychologists) were trained using video recordings of interviews over a 3-day session by WHO-CC experts. The diagnoses of psychotic disorders were confirmed during the study by a senior psychiatrist who is familiar with transcultural psychiatry (Amad et al. 2013).

The designation of migrant status was based on the country of birth of the subject, the subject's parents and the subject's grandparents; and defined a migrant as first generation (a subject born abroad), second generation (at least one parent born abroad), or third generation (at least one grand- parent born abroad). 
The study results reported a high prevalence of psychotic disorders in the migrants in France, which persists into the second generation for single psychotic episodes and into the third generation for the recurrent psychotic disorder, after adjustment for age, sex, level of education and cannabis use. Several explanations have been proposed to account for the increase of psychosis among migrants. One explanation corresponds to the hypothesis of an increased prevalence of psychosis in the country of origin. Other explanations have been proposed to account for the in- crease of psychosis among migrants, such as misdiagnosis, selective migration, genetics, neurodevelopmental factors and substance use as well as the hypothesis that a vitamin $\mathrm{D}$ deficiency may be a contributing factor to psychosis in dark-skinned migrants to European countries (Amad et al. 2013). Nevertheless, it is highly unlikely that these risk factors alone can explain the presence of the increased prevalence of psychotic disorders in the second and third generation.

Bourque et al. (2011) performed a meta-analysis in order to determine the risk of psychotic disorders among second-generation immigrants (SGIs) in comparison with non-migrants and first-generation immigrants (FGIs). Medline, EMBASE and PsycINFO databases were searched systematically for population-based studies on migration and psychotic disorders published between 1977 and 2008. All potential publications were screened by two independent reviewers in a threefold process.

Their review confirms that an increased risk for schizophrenia and related disorders affects not only FGIs, with a personal history of migration, but also SGIs born to one or two migrant parents in the host country. This finding held for nearly all migrant groups identified (Bourque et al. 2011) (Table 2).

\section{CONCLUSION}

Relevant studies indicated that migrant population, compared to others, presented a higher rate of admission for psychotic disorders (Gupta 1993, Haasen et al. 2000, Fossion et al. 2002, McGrath et al. n.d.), as well as higher rates of anxiety disorder, especially among female immigrant population (Kerkenaar et al. 2013, Bekker \& Van Mens-Verhulst 2007).

Meta-analyses have consistently shown that a personal or family history of migration represents an important risk factor for psychosis (Cantor-Graae \& Selten 2005). Furthermore, this risk clearly persists into the second generation, with an incidence ratio of $2.3(95 \%$ CI [1.8-2.5]) (Bourque et al. 2011).

Considering the impact depression has on general well-being, the use of healthcare sources and mortality, overall functioning and given the fact that depression in many cases is considered a treatable disorder, an important public health gains may be possible (Beekman et al. 1999, Charney et al. 2003) and further studies need to explore the etiology of depression in elderly migrants.
Knowledge about the epidemiology of late life depression in migrants may help deciding whether special health or prevention programs are necessary and whether there are specific risk groups (Van der Wurff et al. 2004). Poor social circumstances like low income have been associated with the occurrence of depression in Somali and Bengali elderly immigrants (Cantor-Graae $\&$ Selten 2005) and may be influenced by preventive interventions, like increasing the social support. Clinicians, both in primary care and in specialized mental health centers, should become more alert on depression in elderly migrants (Van der Wurff et al. 2004).

Migrants are often thought to be at higher risk of depressive and anxiety disorders, particularly the firstgeneration, as a result of the stress they have to endure before, during and after migration. Nonetheless, epidemiological evidence on the prevalence of dysphoric disorders among migrants in Europe is still limited and findings are contradictory (Kerkenaar et al. 2013). Whereas some studies found higher rates of depression and anxiety among migrants (Wittig et al. 2008, Tinghog et al. 2007) others assessed rates that were similar to the host population (Glaesmer et al. n.d.).

The prevalence of depressive and anxiety disorders among migrants has been shown to depend on several characteristics of the migrants and host countries. Some studies indicate that refugees had a significantly higher prevalence of depression and anxiety disorders than labor migrants and that a higher gross national product of the host country was related with lower rates of dysphoric disorders among labor migrants, as well as the prevalence of mental illnesses among migrants in different European countries depends on their socioeconomic situation. However, studies about the effect of length of stay in the host country are inconsistent (Kerkenaar et al. 2013).

\section{Acknowledgements: None.}

\section{Conflict of interest: None to declare.}

\section{Contribution of individual authors:}

Study conception and design: Boris llić, Vesna Švab, Biserka Sedić;

Data acquisition and selection: Boris llić, Biserka Sedić;

Manuscript writing and revision: Boris llić, Vesna Švab, Biserka Sedić, Irena Kovačević, Adriano Friganović, Ena Jurić.

\section{References}

1. Amad A, Dewi G, Julia S, Pierre T, Jean-Luc $R$, Guillaume V: Increased prevalence of psychotic disorders among third-generation migrants: Results from the French Mental Health in General Population survey. Schizophrenia Research 2013; 147:193-95. 
2. Anderson B \& Blinder S: Who Counts as a Migrant? Definitions and their Consequences. Briefing, The Migration Observatory, University of Oxford, 2015.

3. Beekman ATF, van Limbeek J, Deeg DJH, Wouters L, van Tilburg $W$ : Screening for depression in the elderly in the community: using the Center for Epidemiologic Studies Depression scale (CES-D) in the Netherlands (in Dutch). T Geron Ger 1994; 25:95-103.

4. Beekman ATF, Copeland JRM, Prince MJ: Review of community prevalence of depression in later life. $\mathrm{Br} J$ Psychiatry 1999; 174:307-11.

5. Bekker, MH \& Van Mens-Verhulst J: Anxiety disorders: sex differences in prevalence, degree, and background, but gender-neutral treatment. Gender Medicine 2007; 4:17893

6. Berkman, LF, Berkman CS, Kasl S, Freeman J DH, Leo L, Ostfeld AM, Cornoni-Huntley J, Brody JA: Depressive symptoms in relation to physical health and functioning in the elderly. Am J Epidemiol 1986; 124:372-88.

7. Bourque F, Van der Ven E, Malla A: A meta-analysis of the risk for psychotic disorders among first- and secondgeneration immigrants. Psychol Med 2011; 41:897-910.

8. Cambridge dictionaries online. n.d. Retrieved March 20, 2016 (http://dictionary.cambridge.org/dictionary/english/migra $n t)$.

9. Cantor-Graae E \& Selten JP: Schizophrenia and migration: a meta-analysis and review. Am J Psychiatry 2005, 162:12-24.

10. Charney DS, Reynolds CF, Lewis L, Lebowitz BP, Sunderland T: Depression and bipolar support alliance consensus statement of the unmet needs in diagnosis and treatment of mood disorders in late life. Arch Gen Psychiatry 2003; 60:664-72.

11. Davies S, Thornicroft G, Leese M, Higgingbotham A, Phelan M: Ethnic differences in risk of compulsory psychiatric admission among representative cases of psychosis in London. Br Med J 1996; 2:533-7.

12. Foelker, GA \& Shewchuk RM: Somatic complaints and the CES-D. J Am Geriatr Soc 1992; 40:259-62.

13. Fossion P, Ledoux Y, Valente F, Servais L, Staner L, Pelc I, Minner P: Psychiatric disorders and social characteristics among second-generation Moroccan migrants in Belgium: An age-and gender-controlled study conducted in a psychiatric emergency department. Eur Psychiatry 2002; 17:443-50

14. Garrison G, Holton A, Neilson D, Owens D, Boot D, Cooper J: Severe mental disorder in Afro-Caribbean patients: some social, demographic service factors. Psychol Med 1989; 19:683-96.

15. Glaesmer H, Wittig U, Brahler E, Martin A, Mewes $R$, Rief $W$ : Are migrants more susceptible to mental disorders? Psychiatr Prax 2009; 36:16-22.

16. Goodman R \& Richards H: Child adolescent psychiatric presentations of second-generation Afro-Caribbeans in Britain. Br J Psychiatry 1995; 167:362-9.

17. Gupta S: Can environmental factors explain the epidemiology of schizophrenia in immigrant groups. Soc Psychiatry 1993; 28: 263-6.

18. Haasen C, Yagdiran O, Mass R, Krausz M: Potential for misdiagnosis among Turkish migrants with psychotic disorders: a clinical controlled study in Germany. Acta Psychiatr Scand 2000; 101:125-9.

19. Harrison G, Glazebrook C, Brewin J, Cantwell R, Dalkin $T$ : Increased incidence of psychotic disorders in migrants from the Caribbean to the United Kingdom. Psychol Med 1997: 27:799-806.

20. Harrison $G$, Owens D, Holton D, Neilson D, Boot D: A prospective study of severe mental disorders in AfroCaribbean patients. Psychol Med 1988; 18:643-57.

21. Harrison G: Searching for the causes of schizophrenia: the role of migrant studies. Schizophr Bull 1990; 16:66371.

22. Ilić B, Cimenti L, Gallina L, Jurić E: Potential terrorism and its impact on mental health. 23rd Days of Psychiatric Nursing Society of Croatian Nurses Association. Rab, Croatia, 2017.

23. Kerkenaar MM, Maier $M$, Kutalek $R$, Lagro-Janssen ALM, Ristl R, Pichlhöfer O: Depression and anxiety among migrants in Austria: A population based study of prevalence and utilization of health care services. J Affect Disord 2013; 151:220-8.

24. Koffman J, Fulop NJ, Pashley D, Coleman K: Ethnicity use of acute psychiatric beds: one-day survery in North and South Thames regions. $\mathrm{Br} J$ Psychiatry 1997; 171:238-41.

25. Lindert J, Schouler-Ocak M, Heinz A, Priebe S: Mental health, health care utilisation of migrants in Europe. Eur Psychiatry 2008; 23:14-20.

26. Littlewood $R$ \& Lipsedge M: Psychiatric illness among British Afro-Caribbeans. Br Med J 1998; 296:950-1.

27. McGovern $D \& R$ Cope: First psychotic admission rates of first-and-second-generation African-Caribbeans. Soc Psychiatry 1987; 22:139-49.

28. McGrath J, Saha S, Welham J, Saadi OE, MacCauley C, Chant D: A systematic review of the incidence of schizophrenia: the distribution of rates and the influence of sex, urbanicity, migrant status and methodology. BMC Med 2004; 2:13.

29. Moher D, Liberati A, Tetzlaff J, Altman DG, The PRISMA Group: Preferred Reporting Items for Systematic Reviews and Meta-Analyses: The PRISMA Statement. BMJ 2009; (339). Retrieved April 03, 2016 (http://prismastatement.org/documents/PRISMA\%202009\%20flow\%20d iagram.doc).

30. Norman P, Boyle P, Rees P: Selective migration, health and deprivation: a longitudinal analysis. Soc Sci Med 2005; 60:2755-71.

31. Oxford dictionaries. Retrieved March 20, 2016 (http:// www.oxforddictionaries.com/definition/english/migrant)

32. Oxford dictionaries. Retrieved March 20, 2016 (http:// www.oxforddictionaries.com/definition/english/immigrant)

33. Perkins RE \& Moodley P: Perception of problems in psychiatric patients: denial, race, service usage. Soc Psychiatry Psychiatr Epidemiol 1993; 28:189-93.

34. Oureshi A, Collazos F, Sobradiel N, Eiroa-Orosa FJ, Febrel M, Revollo-Escudero HW, Andrés E, Mar Ramos $M$, Roca M, Casas M, Serrano-Blanco A, Escobar JI, Garcia-Campayo J: Epidemiology of psychiatric morbidity among migrants compared to native born population in Spain: a controlled study. Gen Hosp Psychiatry 2013; 35:93-99.

35. Reus-Pons M, Kibele EUB, Janssen F: Differences in healthy life expectancy between older migrants and nonmigrants in three European countries over time. Int $J$ Public Health 2017; 62:531-40.

36. Rwegellera GG: Differential use of psychiatric services by West Indians, West Africans English in London. Br J Psychiatry 1980; 137:428-32. 
37. Selten $J$ \& Sijben N: First admission rates for schizophrenia in immigrants to The Netherlands. The Dutch National Register. Soc Psychiatry Psychiatr Epidemiol 2001; 178:367-72.

38. Selten JP, Veen N, Feller W, Bloom JD, Schols D, Camoenie $W$ et al.: Incidence of psychotic disorders in immigrant groups to The Netherlands. Br J Psychiatry 2001; 178:367-72.

39. Silveira ER \& Ebrahim S: Social determinants of psychiatric morbidity and well-being in immigrants elders and whites in east London. Int J Geriatr Psychiatry 1998; 13:801-12.

40. Termorshuizen F, Wierdsma AI, Visser E, Drukker M, Sytema S, Laan W, Smeets HM, Selten JP: Psychosis and suicide risk by ethnic origin and history of migration in the Netherlands. Schizophr Res 2012; 138:268-73.

41. Tinghog P, Hemmingsson T, Lundberg I: To what extent may the association between immigrant status and mental illness be explained by socioeconomic factors? Soc Psychiatry Psychiatr Epidemiol 2007; 42:990-6.
42. Ustun TB: WHO Perspectives on international classification. Psychopathology 2002; 35:62-6.

43. Van der Wurff FB, Beekman ATF, Dijkshoorn H, Spijker JA, Smits CHM, Stek ML, Verhoeff A: Prevalence and riskfactors for depression in elderly Turkish and Moroccan migrants in the Netherlands. J Affect Disord 2004; 83:33-41.

44. Veling $W$, Hoek HW, Selten JP, Susser E: Age at migration and future risk of psychotic disorders among immigrants in the Netherlands: a 7-year incidence study. Am J Psychiatry 2011; 168:1278-85.

45. Veling $W$, Selten JP, Veen $N$, Laan W, Blom JD, Hoek $H W$ : Incidence of schizophrenia among ethnic minorities in the Netherlands: a four-year first- contact study. Schizophr Res 2006; 86:189-93.

46. Wessley S, Castle D, Der G, Murray R: Schizophrenia and Afro-Caribbeans. A Case-control study. Br J Psychiatry 1991; 159:795-801.

47. Wittig U, Lindert J, Merbach M, Brahler E: Mental health of patients from different cultures in Germany. Eur Psychiatry 2008; 23:28-35.

\section{Correspondence:}

Boris Ilić, MSN, RN, PhD candidate

Department of Nursing, University of Applied Health Sciences

Mlinarska cesta 38, HR-10000 Zagreb, Croatia

E-mail:boris.ilic@zvu.hr 